01

\title{
Численное изучение процесса локализации пластической деформации на примере высокоскоростного сжатия полого монокристаллического цилиндра
}

\author{
(C) А.И. Дмитриев, ${ }^{1,2,3}$ А.Ю. Никонов, ${ }^{1,2}$ М.П. Бондарь ${ }^{4}$ \\ ${ }^{1}$ Институт фризики прочности и материаловедения СО РАН, \\ 634055 Томск, Россия \\ ${ }^{2}$ Томский государственный университет, \\ 634050 Томск, Россия \\ ${ }^{3}$ Томский политехнический университет, \\ 634050 Томск, Россия \\ ${ }^{4}$ Институт гидродинамики им. акад. Лаврентьева СО РАН, \\ 630090 Новосибирск, Россия \\ e-mail: dmitr@ispms.ru
}

(Поступило в Редакцию 3 июня 2015 г. В окончательной редакции 1 марта 2016 г.)

Исследовано влияние кристаллографической ориентации монокристаллического полого цилиндра на особенности зарождения и развития в нем пластической деформации в условиях высокоскоростного осесимметричного нагружения. Преимуществом предлагаемой схемы нагружения является одновременная реализация всех вариантов нагружения в рамках выбранной кристаллографической плоскости основания цилиндра, а также достижения различных степеней деформации вдоль сечения образца. С использованием молекулярно-динамического моделирования показано различие в деформационных свойствах нагружаемого образца в зависимости от выбранной кристаллографической ориентации плоскости основания. Результаты исследования могут быть использованы для понимания основных механизмов пластического деформирования кристаллических тел.

\section{Введение}

Несмотря на достигнутый определенный прогресс, связанный с использованием как современных экспериментальных методов исследования, так и новых теоретических подходов, вопросу изучения особенностей локализации пластической деформации в кристаллических материалах по-прежнему уделяется пристальное внимание [1-3]. Повышенный интерес вызван тем, что понимание основных механизмов пластического деформирования кристаллических тел напрямую связано с возможностью управления их прочностными и деформационными характеристиками.

Следует отметить, что чаще всего явление локализации деформации рассматривается для случаев больших степеней, высоких скоростей и температур деформирования. Это проявляется в виде формирующихся стационарных полос, называемых также термином „shear bands“ и представляющих собой области материала, в которых скорости деформации намного выше скоростей деформации в остальных объемах [4,5]. Образование „shear bands“ играет решающую роль при дальнейшем деформировании, поскольку в большинстве случаев они являются предвестником разрушения материала. В то же время известно, что по мере роста деформации масштаб проявления ее локализации изменяется от блока к зерну, от зерна к комплексу зерен и далее к образцу в целом. Таким образом, этот процесс является многоуровневым. Следовательно, начальный этап зарождения и развития процесса локализации деформации неразрывно связан с особенностями отклика материала на нагрузку на микромасштабе [6-8]. При переходе на микромасштаб большое значение приобретают исследования, проводимые на монокристаллах. Так, в работе [9] было показано, что величина деформации, при которой формируются полосы локализованного сдвига в монокристаллических образцах сплава $\mathrm{Al}-2.8 \% \mathrm{Cu}$ зависит от ориентации кристаллической решетки по направлению к прикладываемому нагружению.

В работе [10], посвященной высокоскоростному осесимметричному нагружению монокристаллов меди, отмечается, что пространственное положение очагов локализации деформации определяется кристаллографией действующих систем скольжения. Таким образом, очередность подключения того или иного плотноупакованного направления скольжения определяется величиной соответствующего фактора Шмида. Отметим, что в цитируемой работе используется методика взрывного нагружения полого толстостенного цилиндра. Преимуществом такого подхода является возможность сочетания в рамках одного эксперимента всех возможных ориентаций монокристалла относительно приложенной нагрузки в плоскости, определенной плоскостью основания образца. Несмотря на указанные преимущества, вопрос о влиянии выбранной кристаллографической плоскости, параллельной основанию самого цилиндрического образца, в работе остается не исследованным. Поиск ответа на данный вопрос предполагает проведение серии испытаний по осесимметричному нагружению полых монокристаллических цилиндров с различной кристал- 
лографической ориентацией их основания. Поскольку для экспериментального решения поставленной задачи необходима трудоемкая подготовка соответствующих монокристаллических образцов, то с учетом малости их пространственных масштабов данный вопрос может быть эффективно исследован с использованием современных методов компьютерного моделирования [11-13].

Таким образом, целью настоящей работы являлось теоретическое исследование зарождения и развития процесса локализации деформации на масштабе отдельных атомов в зависимости от кристаллографической ориентации плоскости основания полого цилиндрического образца при его высокоскоростном осесимметричном нагружении. Для верификации компьютерной модели предлагается использовать имеющиеся экспериментальные данные по высокоскоростному нагружению монокристаллического образца меди, описанные в работе [10].

\section{Данные экспериментальных исследований}

В цитируемой работе [10] проведены результаты экспериментального исследования особенностей формирования микроструктуры в монокристаллах меди, нагруженных методом взрывного коллапса полого толстостенного цилиндра. Монокристаллы меди имели форму трубок с внутренним диаметром $11 \mathrm{~mm}$ и толщиной стенки $3 \mathrm{~mm}$ и длиной $30 \mathrm{~mm}$. Ориентация монокристалла была такова, что ось цилиндра соответствовала кристаллографическому направлению [134]. Нагружение проводилось при контролируемых параметрах детонации, обеспечивающих необходимое давление для коллапса при радиальном движении материала цилиндра. Скорость деформации достигала $\dot{\varepsilon} \approx 5 \cdot 10^{4} \mathrm{~s}^{-1}$. Характерный вид результирующей микроструктуры сколлапсированного монокристалла приведен на рис. 1 .

Представленные результаты показывают, что в условиях высокоскоростного осесимметричного нагружения монокристалла в процесс деформирования включаются все активные плотноупакованные системы скольжения. Очередность активности систем скольжения зависит от значения сдвиговых напряжений, определяемых из выражения

$$
\tau=m \sigma,
$$

где $m-$ фактор Шмида, а $\sigma-$ приложенное напряжение.

\section{Результаты компьютерного моделирования}

\section{Нагружение образца с плоскостью основания [134]}

Для проведения исследований по высокоскоростному нагружению монокристаллического образца меди

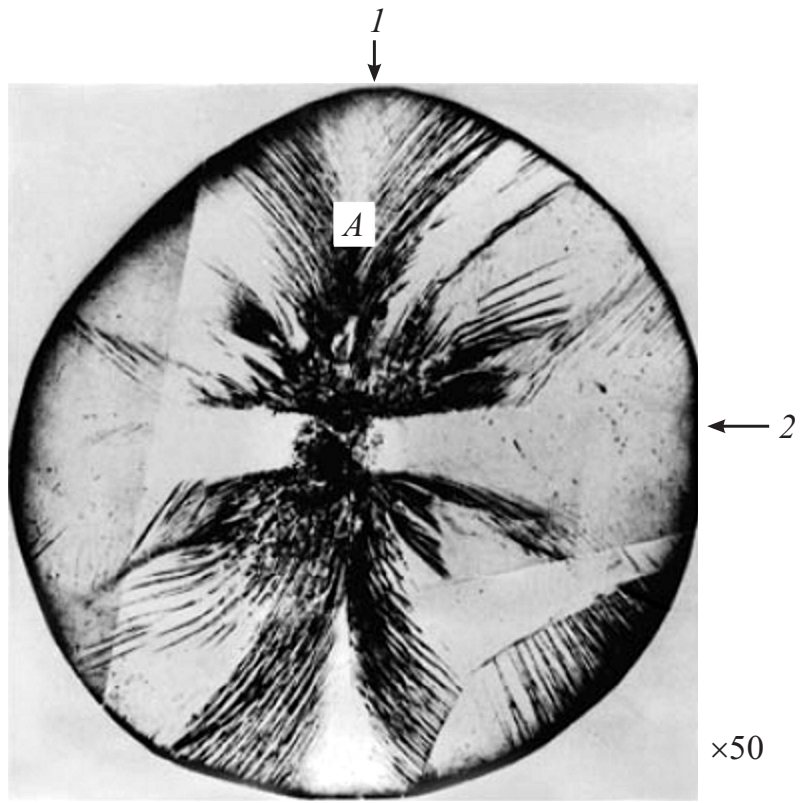

Рис. 1. Микроструктура сколлапсированного монокристалла [10]. 1 и 2 - направления нагружения, соответствующие кристаллографическим направлениям $[04 \overline{3}]$ и $[11 \overline{1}]$ монокристалла.

на масштабе отдельных атомов был выбран метод молекулярной динамики в виде программного пакета LAMMPS [14]. Взаимодействие между частицами описывалось с помощью метода погруженного атома $[12,15]$. Физическая корректность используемого программного пакета и межатомного потенциала проверялась на основе сопоставления рассчитываемых значений энергии образования вакансии и дефекта упаковки с аналогичными экспериментальными данными. Отклонение в обоих случаях составило менее $1 \%$.

Моделируемый образец представлял собой полый бездефектный медный цилиндр, ось симметрии которого, как показано на рис. 2, была направлена вдоль оси $Z$ лабораторной системы координат. Внутренний и внешний радиусы цилиндра составляли 3.55 и $14.46 \mathrm{~nm}$. Высота цилиндра задавалась равной $10.845 \mathrm{~nm}$. Ориентация кристаллической решетки моделируемого кристаллита была выбрана в соответствии с кристаллографической ориентацией образца, описанного в работе [10]. Таким образом, оси лабораторной системы координат $X, Y$ и $Z$ соответствовали кристаллографическим направлениям $[11 \overline{1}],[\overline{7} 5 \overline{2}]$ и [134]. Осесимметричное нагружение моделировалось путем задания атомам, расположенным на внешней поверхности цилиндра, постоянных значений скоростей. Действие скоростей было направлено к центру цилиндра в плоскости, параллельной плоскости основания образца, а значения модулей скоростей были равны $10 \mathrm{~m} / \mathrm{s}$. Толщина нагружаемого слоя составляла $0.5 \mathrm{~nm}$. Вдоль оси цилиндра $Z$ задавались периодические граничные условия. Исходная кинетическая температура моделируемого образца составляла $140 \mathrm{~K}$. 


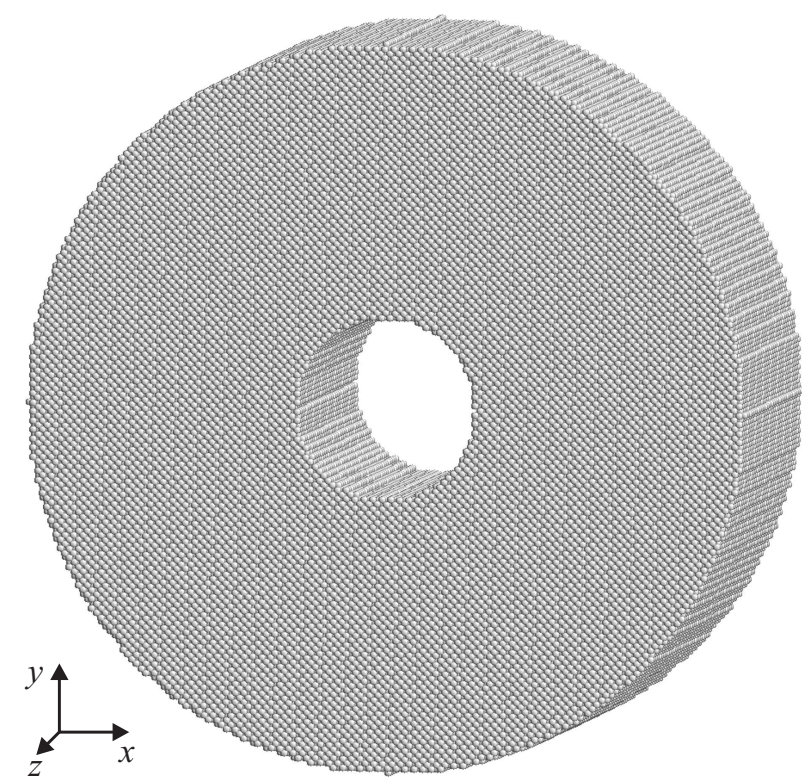

Рис. 2. Исходная структура моделируемого кристаллита.

Для интегрирования уравнений движения использовался скоростной алгоритм Верле. Полное число атомов превышало 500000.

В работе с использованием алгоритма поиска изменения локальной топологии атомных связей [16] анализировалась эволюция структуры образца в результате действия приложенного осесимметричного сжатия. Обнаружено, что сжимающая деформация при достижении определенного значения приводит к образованию на внутренней поверхности цилиндра дефектов структуры. На рис. 3 представлена эволюция структуры моделируемого кристаллита, где приведены только атомы, локальная топология атомных связей которых отличается от исходной ГЦК-решетки. На рис. 2 серым цветом отмечены атомы, расположенные на внешней и внутренней свободных поверхностях. Темным цветом отмечены атомы с ГПУ локальной топологией атомных связей. Хорошо видно, что полосы локализованных атомных смещений, образующиеся на внутренней поверхности полого цилиндра, сформированы преимущественно из атомов с локальной топологией атомных связей, близких к ГПУ-решетке. Таким образом, получаемые дефекты структуры соответствуют дефектам упаковки. По мере нагружения моделируемого образца число дефектов упаковки растет, и они распространяются от внутренней свободной поверхности, где достигаются максимальные значения деформации, в объем материала.

Как и в случае результатов экспериментальных исследований при численном моделировании, можно также выделить последовательность в образовании полос локализованных атомных смещений в нагружаемом образце. Первоначально полосы возникают в плоскости (11) $)$, которая расположена под углом $90^{\circ}$ к плоскости основания цилиндра (рис. $3, a$ ). Затем начинают образовываться

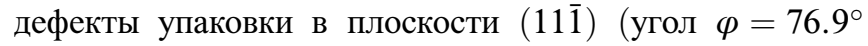
к основанию цилиндра) (рис. $3, b)$. Третьей плоскостью скольжения становится (111) с углом разориентации $\varphi=47.2^{\circ}$ (рис. 3,c). Последними появляются дефекты упаковки в плоскости (111) (угол разориентации $\left.\varphi=25.1^{\circ}\right) \quad($ рис. 3,d). Таким образом, в последовательности формируемых полос локализованных атомных смещений прослеживается очередность, связанная с увеличением величины угла разориентации плоскости основания цилиндра с соответствующей плоскостью скольжения. Полученный результат находится в полном соответствии с физикой изучаемого явления и хорошо согласуется с данными экспериментальных исследований. Так, в процессе локализации пластической деформации участвуют те же плоскости и направления скольжения $(\{111\},\langle 110\rangle)$, что и отмеченные в работе [10]. Механизм деформирования имеет явный дислокационный характер. Очередность активности систем скольжения определяется величиной фактора Шмида (от большего значения к меньшему). В частности, в системах

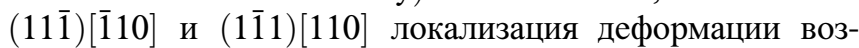
никает практически одновременно, что подтверждается близкими значениями фактора Шмида, равными 0.48 и 0.47 соответственно.

\section{Результаты нагружения образцов с плоскостями основания (001) и (111)}

Для исследования влияния кристаллографической ориентации плоскости основания цилиндрического образца на его деформационные свойства в работе моделировалось высокоскоростное осесимметричное нагружение образцов из монокристалла меди, форма и размеры которых были аналогичны рассмотренному выше случаю. Отличие заключалось в том, что оси цилиндров на данном этапе исследования были перпендикулярны кристаллографическим направлениям [001] и [111] медного образца. Размеры внутреннего и внешнего радиусов обоих цилиндров составляли 10 и 40 параметров решетки меди (3.615 и $14.46 \mathrm{~nm}$ соответственно). Высота цилиндра в обоих случаях была $10.845 \mathrm{~nm}$. Осесимметричное сжатие, как и в предыдущем случае, моделировалось путем задания атомам, расположенным на внешней поверхности цилиндра, постоянных значений скорости $10 \mathrm{~m} / \mathrm{s}$. Толщина нагружаемого слоя составила $0.5 \mathrm{~nm}$. Вдоль оси цилиндра задавались периодические граничные условия. Результирующее число атомов превышало 500 000. Исходная температура образца, рассчитанная из равенства кинетической и тепловой энергии кристаллита, составляла $\sim 140 \mathrm{~K}$. В обоих примерах анализировалась эволюция структуры кристаллита в результате действия приложенного внешнего нагружения.

Как и ранее, при достижении определенных степеней деформации в полых цилиндрах на их внутренних свободных поверхностях происходит формирование дефектов структуры. Использование алгоритма по анализу локальной топологии атомных связей в кристалличе- 

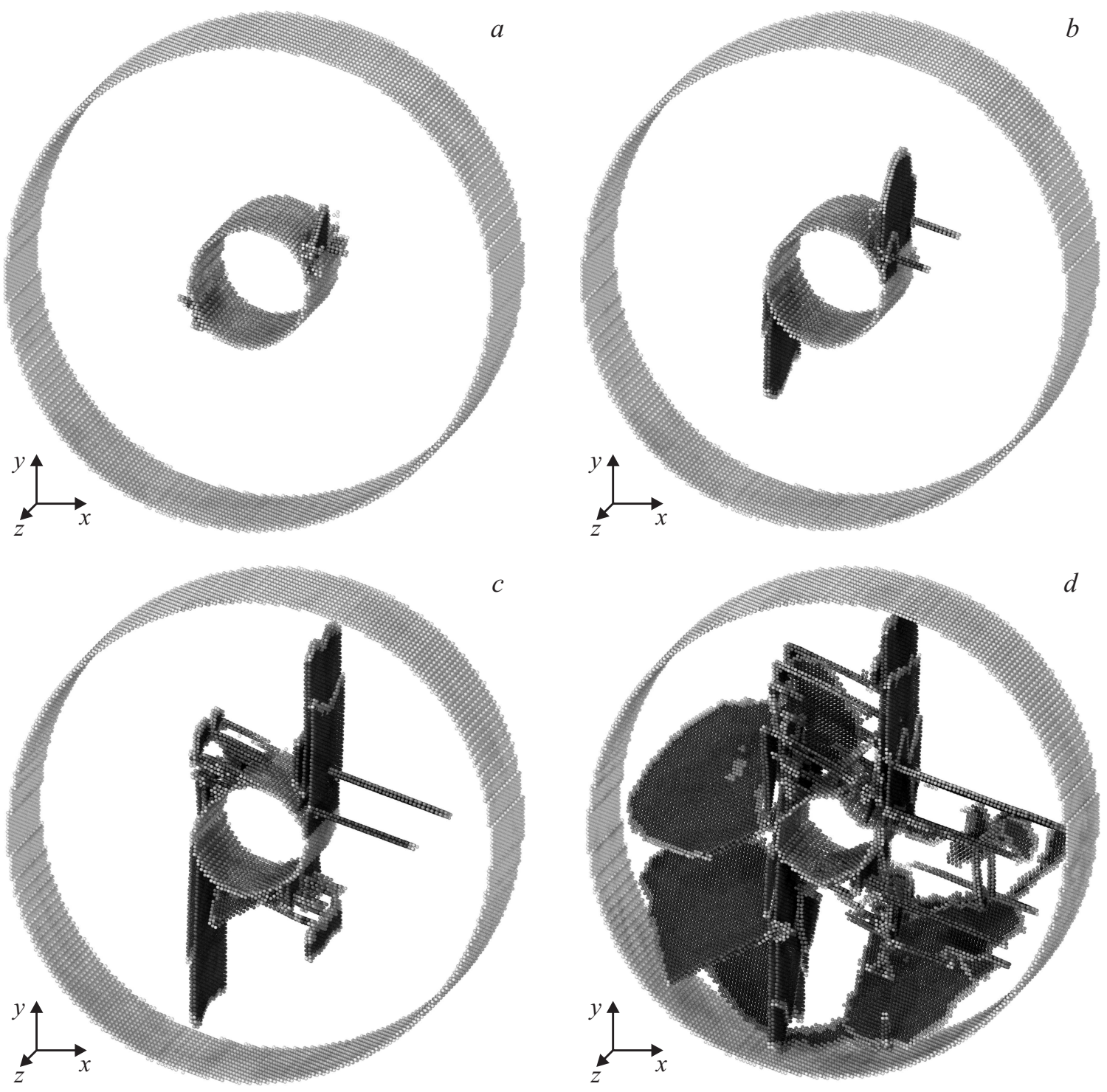

Рис. 3. Трехмерное изображение структуры моделируемого кристаллита на стадии локализации деформации в различные моменты времени: $a-26, b-28, c-33, d-47 \mathrm{ps}$.

ской решетке позволило выявить образование отдельных плоскостей с ГПУ-конфигурацией. Таким образом, развитие пластической деформации в моделируемых монокристаллах происходит за счет образования дефектов упаковки. На рис. 4 представлены структуры для обоих моделируемых кристаллитов в последовательные моменты времени. Для лучшей визуализации результатов отмечены только атомы, имеющие локальную топологию атомных связей, отличную от ГЦК-решетки. Серым цветом выделены атомы, расположенные вблизи свободных поверхностей цилиндра. Темным цветом отмечены атомы с ГПУ локальной топологией атомных связей. Видно, что по мере нагружения моделируемого образца число дефектов структуры растет, и они распространяются от внутренней свободной поверхности, где вследствие осесимметричного сжатия достигаются максимальные значения деформации, в объем материала.
Отметим, что зарождение дефектов структуры для образца с ориентацией основания (001) начинается в момент времени $t=38 \mathrm{ps}$, в то время как для образца с ориентацией основания (111) этот процесс происходит уже при $t=27 \mathrm{ps}$. Отличие между поведением обоих нагружаемых кристаллитов заключается также в очередности формируемых дефектов структуры. Так, для образца с кристаллографической ориентацией основания (001), как и в случае образца с ориентацией основания (134), можно проследить очередность активности систем скольжения, связанную с уменьшением величины угла разориентации оси цилиндра с соответствующей плоскостью. Особенность образца с ориентацией основания (111) заключается в том, что все возможные плоскости скольжения для него разориентированы с осью цилиндра на одинаковый угол $\varphi=60^{\circ}$. Таким образом, очередности активности систем скольжения в 

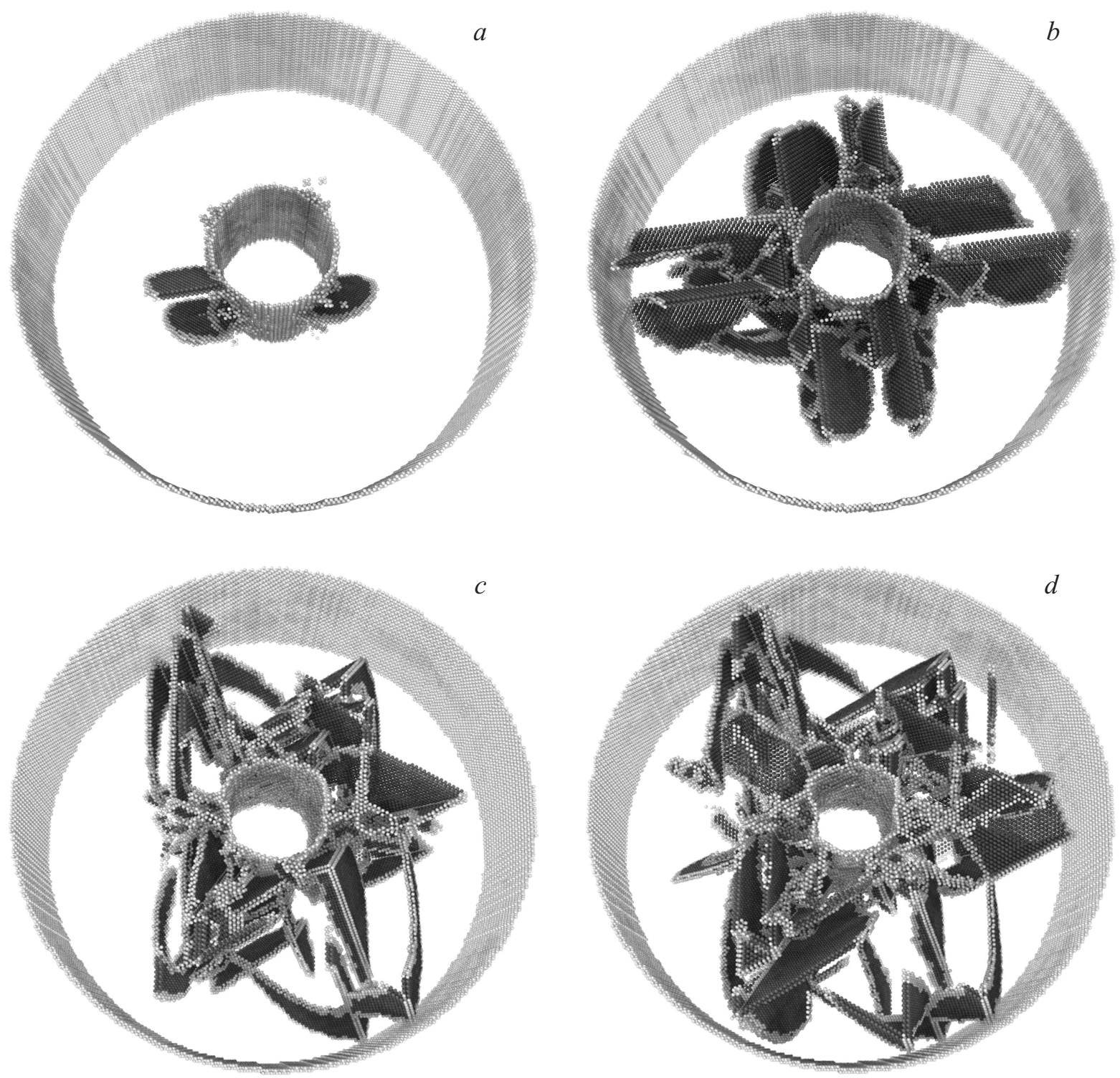

Рис. 4. Трехмерное изображение структуры моделируемых кристаллитов на стадии локализации деформации в различные моменты времени. Для цилиндра с ориентацией основания (001): $a-t=39 \mathrm{ps}, b-t=45 \mathrm{ps}$. Для цилиндра с ориентацией основания (111): $c-t=39 \mathrm{ps}, d-t=45 \mathrm{ps}$.

нем не наблюдается, а полосы локализованных атомных смещений образуются в нем одновременно по всем возможным плоскостям скольжения.

\section{Влияние кристаллографической ориентации}

В работе была проведена оценка величин деформаций, при которых в кристаллитах возникают локализованные атомные смещения. Величина деформации рассчитывалась по следующей формуле:

$$
\varepsilon=\ln \left(r_{0} / r\right),
$$

где $r$ и $r_{0}$ - текущее и начальное расстояния от центра цилиндра до выделенных атомов. Результаты расчетов деформации в зависимости от времени нагружения для цилиндра с ориентацией основания (001) показаны на рис. 5. Положение выделенных атомов в образце, для которых рассчитывалось значение деформации, отмечено на рис. 5 в верхнем левом углу. Вдоль оси $Z$ атомы выбирались в атомной плоскости, расположенной в середине образца.

Согласно приведенным результатам, деформация различных частей цилиндра до момента зарождения полос согласованных атомных смещений носит преимущественно однородный характер. Небольшое отличие скорости перемещения для атомов 1 и 2 обусловлено их близостью к свободной поверхности. Начиная с момента времени $\sim 40$ ps наблюдается резкое увеличение скорости деформации для областей кристаллита, расположенных на внутренней поверхности. 


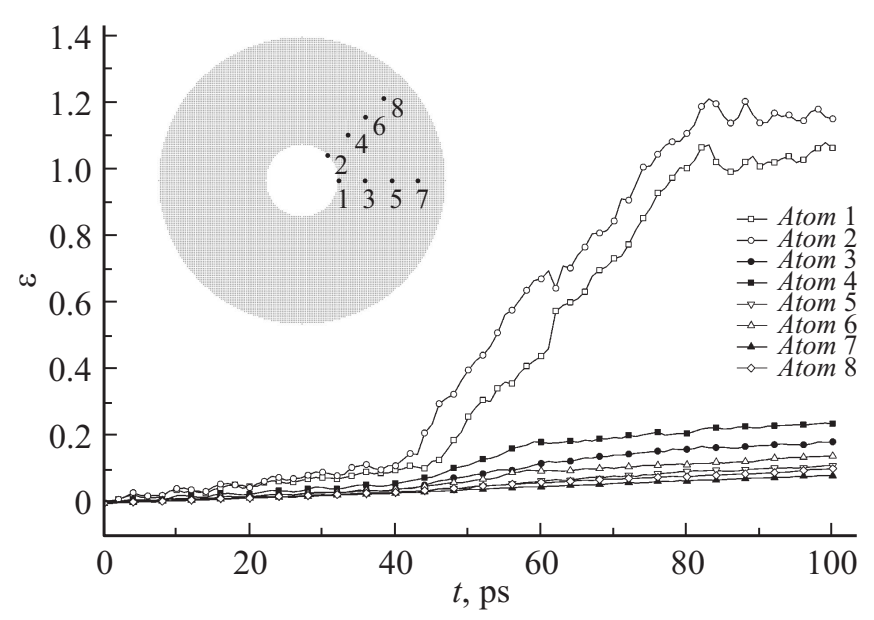

Рис. 5. Зависимость рассчитываемой величины деформации для выбранных атомов от времени.
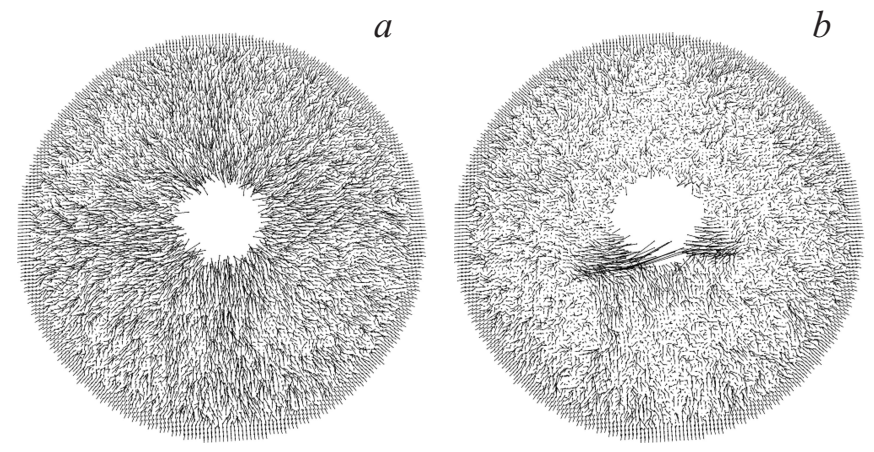

Рис. 6. Смещения атомов центрального слоя цилиндра в интервалы времени: $a-\mathrm{c} t=34 \mathrm{ps}$ по $t=36 \mathrm{ps}$ и $b-\mathrm{c} t=37 \mathrm{ps}$ по $t=39 \mathrm{ps}$.

Наблюдаемое отличие в величине смещений различных групп атомов обусловлено формированием дефектов структуры вблизи внутренней свободной поверхности кристаллита. На рис. 6 показаны траектории движения атомов для центрального слоя цилиндра в последовательные моменты времени. Момент формирования локализованных полос смещений атомов хорошо прослеживается в интервале времени с 37 по $39 \mathrm{ps}$ (рис. $6, b$ ), притом что на предыдущем интервале времени неоднородного распределения смещений не наблюдается (рис. 6, $a$ ).

Сопоставление зон локализации атомных смещений с локальной топологией атомных связей показало, что смещения атомов реализуются в местах сформировавшихся структурных дефектов - дефектов упаковки. Это видно из сравнения траектории атомов, изображенных на рис. $6, b$, и рис. 7 , где показана локальная топология атомных связей для атомов того же выделенного центрального слоя кристаллита. На рис. 7 серым цветом отмечены атомы с ГЦК-топологией атомных связей (бездефектная часть кристаллита), а темным цветом показаны атомы с локальной ГПУ-топологией межатомных связей.
Согласно полученным результатам, поведение областей кристаллита вблизи внутренней свободной поверхности в большей степени определяется особенностями структурной перестройки кристаллической решетки вследствие осесимметричного сжатия. Так, дальнейшее снижение величины скорости деформации для атомов 1 и 2 в момент времени $\sim 80 \mathrm{ps}$ (рис. 5) обусловлено схлопыванием внутренней полости цилиндра. Характер смещения атомов 3 и 4 также отличается от остальных групп выделенных атомов. Таким образом, в качестве представительных областей, по поведению которых можно оценивать деформационные свойства моделируемых монокристаллов, могут быть рассмотрены области цилиндра, удаленные от его оси на величину не менее полутолщины стенки.

Для сравнения деформационных свойств образцовцилиндров с различной кристаллографической ориентацией их основания в работе рассчитывалось среднее значение деформации по 8 атомам, лежащим в слое, удаленным от оси цилиндра на то же расстояние, что и атомы 5 и 6 на рис. 5. Положение атомов, используемых для оценки величины средней деформации, отличалось на $45^{\circ}$ по отношению к оси цилиндра. Результирующие

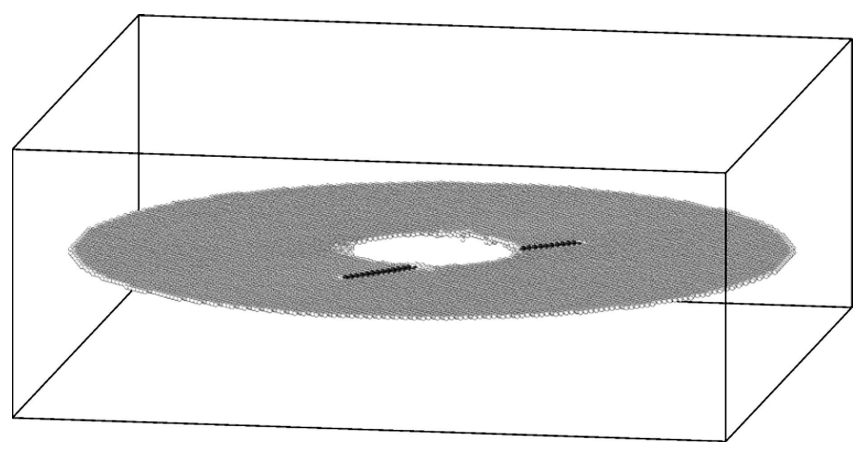

Рис. 7. Центральный слой моделируемого цилиндра в момент времени $t=39 \mathrm{ps}$.

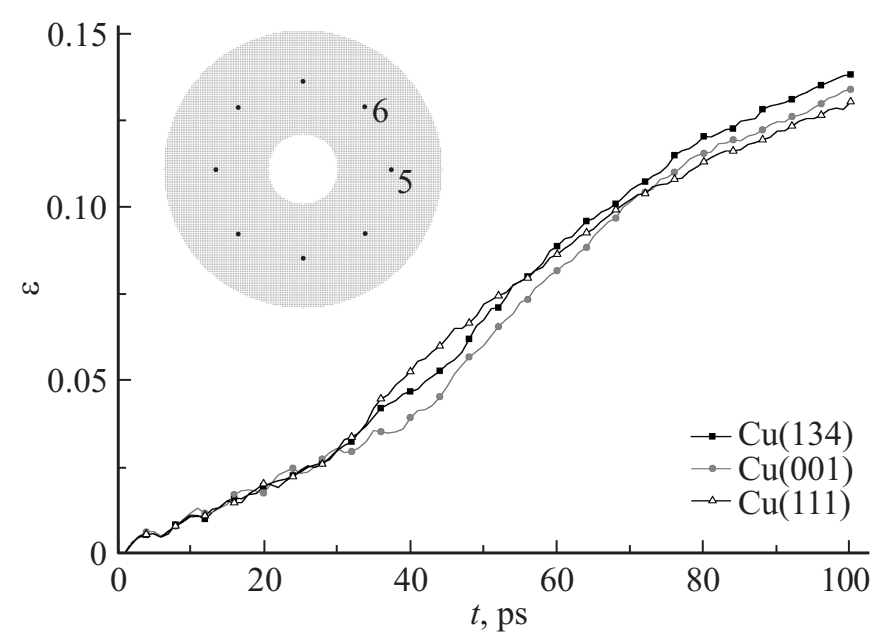

Рис. 8. Усредненное значение деформации для образцов меди с различной кристаллографической ориентацией их основания. 
временные зависимости величины средней деформации для трех рассмотренных кристаллитов с различной кристаллографической ориентацией основания приведены на рис. 8. Схематическое изображение положения атомов, используемых для усреднения величины деформации, изображено в верхнем левом углу.

Результаты моделирования показали, что стадия упругого деформирования для всех рассмотренных вариантов совпадает до величины деформации 0.03. Дальнейшее нагружение приводит к тому, что скорость деформирования образцов с основанием (111) и (134) возрастает по сравнению с образцом с ориентацией основания (001), для которого эта стадия продолжается до деформации 0.04. При больших степенях нагружения скорость деформации образца с основанием (111) замедляется и становится минимальной из всех рассмотренных вариантов. Такой характер зависимости, по-видимому, обусловлен относительно ранним формированием большого числа дефектов упаковки при одновременной активации всех возможных плоскостей скольжения. Наличие множества дефектов структуры приводит в дальнейшем к упрочнению такого образца. Что касается образцов с ориентациями основания (001) и (134), то на протяжении всей активной стадии нагружения рассчитанная величина средней деформации для варианта (134) расположена выше аналогичной величины для варианта (001).

\section{Заключение}

На основе полученных результатов исследования процесса пластического деформирования полого монокристаллического цилиндра в условиях высокоскоростного осесимметричного сжатия можно сформулировать следующие выводы.

- Разработанная компьютерная модель осесимметричного динамического нагружения кристаллита меди на масштабном уровне отдельных атомов показала хорошее согласие результатов моделирования с экспериментальными данными по взрывному нагружению монокристаллов меди. Как в эксперименте, так и в компьютерной модели отмечена очередность активации действующих систем скольжения, которая определяется величиной соответствующего значения фактора Шмида. Таким образом, предложенная численная модель может быть использована для исследования особенностей зарождения и развития пластической деформации в кристаллических материалах.

- С использованием компьютерной модели показано влияние выбранной кристаллографической плоскости, основания цилиндрического образца на очередность подключения систем скольжения и результирующие деформационные свойства моделируемого объекта. Так, в образце, плоскость основания которого параллельна кристаллографической плоскости (111), очередности активации систем скольжения не наблюдается, а генерируемые полосы локализованных атомных смещений образуются в нем одновременно по всем возможным плоскостям скольжения. Такой характер отклика кристаллита на внешнее нагружение приводит к тому, что его скорость деформирования является максимальной из трех рассмотренных в работе вариантов образцов на начальных этапах пластического поведения. В ходе дальнейшего нагружения относительно ранняя активация всех возможных плоскостей скольжения приводит к замедлению скорости деформирования такого образца и на заключительном этапе нагружения она становится минимальной из всех рассмотренных конфигураций.

Полученные в работе результаты экспериментального и теоретического исследования могут быть использованы при изучении закономерностей развития локализации пластической деформации в материалах с кристаллической основой.

Работа выполнена в рамках Программы фундаментальных научных исследований государственных академий наук на 2013-2020 гг., а также при поддержке программы Научного фонда им. Д.И. Менделеева ТГУ в 2015 г. № 8.1.18.2015.

\section{Список литературы}

[1] Boehler J.P., Khan A.S. Anisotropy and Localization of Plastic Deformation. Springer, 1991. $702 \mathrm{p}$.

[2] Zuev L.B., Barannikova S.A. // International J. Mechanical Sciences. 2014. Vol. 88. P. 1-7.

[3] Yoon S.C., Krishnaiah A., Chakkingal U., Kim H.S. // Computational Materials Science. 2008. Vol. 43(4). P. 641-645.

[4] Wang X.D., Qu R.T., Liu Z.Q., Zhang Z.F. // Materials Science and Engineering. A. 2015. Vol. 627. P. 336-339.

[5] Беликова А.Ф., Буравова С.Н., Гордополов Ю.А. // ЖТФ. 2013. Т. 83. Вып. 2. С. 153-155.

[6] Бондарь М.П., Мержиевский Л.А. // ФГВ. 2006. Т. 42. № 3. C. 121-131.

[7] Дмитриев А.И., Псахье С.Г. // Письма в ЖТФ. 2004. Т. 30. Вып. 14. С. 8-12.

[8] Бондарь М.П., Псахье С.Г., Дмитриев А.И., Никонов А.Ю. // Физ. мезомех. 2013. Т. 16. № 2. С. 5-13.

[9] Harren S.V., Deve Y.T., Asaro R.J. // Acta Metall. 1988. Vol. 36(9). P. 2435-2480.

[10] Бондарь М.П. // ФГВ. 2003. Т. 9. № 1. С. 128-131.

[11] Österle W., Dmitriev A.I., Kloß H. // Tribol. Lett. 2014. Vol. 54. P. 257-262.

[12] Alam M., Groh S. // J. of Physics and Chemistry of Solids. 2015. Vol. 82. P. 1-9.

[13] Псахье С.Г., Зольников К.П., Дмитриев А.И., Смолин А.Ю., Шилько Е.В. // Физ. мезомех. 2013. Т. 16. № 4. C. 29-37.

[14] Plimpton S.J. // J. Comp. Phys. 1995. Vol. 117. N 1. P. 1-19.

[15] Suzuki A., Mishin Y. // Interface Sci. 2003. Vol. 11. N 1. P. 131-148.

[16] Honeycutt D.J., Andemen H.C. // J. Phys. Chem. 1987. Vol. 91. P. 4950-4963. 